\title{
Potential Genotoxic and Cytotoxic Effects of Plant Extracts
}

\author{
Tülay Askin Celik \\ Adnan Menderes University, Faculty of Art and Science, \\ Department of Biology, Aydin, \\ Turkey
}

\section{Introduction}

The medicinal use of plants is probably as old as human kind itself. The World Health Organization (WHO) estimates that up to $80 \%$ of the world's population relies on traditional medicinal system for some aspect of primary health care (Farnsworth et al., 1985) and the traditional medicines are generally more acceptable from a cultural and spiritual perspective. Many of the plants species used for this purpose have been found to contain therapeutic substances which can be extracted and used in preparation of drugs, but the plant itself can also be used either directly or as an extract for medication, a practice that is particularly popular in developing countries (Ishii et al., 1984; Hoyos et al., 1992). Two hundred and fifty years ago there were few or no synthetic medicines and species of higher plants were the main source of medicines for the World (Duke, 2003). The method of discovery of medicines was probably trial and error that related the cause-and effect-relationship to the use of the plant or animal part and a desired result. People used to the whole plant or some part of the plant (leaves, bark, roots, seeds and fruits), animals, their organs and glands for the therapeutic purpose, e.g., cinchona bark, digitalis leaf, ephedra aerial parts, poppy capsule, hog testes, etc (http:/www.mosby.com/MERLIN/drug_card_update/history_drug_development.htm.)

Many of the drugs, which we use today are based on folk remedies and subsequent ethnopharmacological studies. There are more than 100 drugs of known structure that are extracted from higher plants and used in allopathic medicine (Cox, 1994; Fransworth, 1990). More than hundred years old drugs like morphine, digitalis and atropine are the time honoured remedies. Further, pharmaceutical preparations were discovered that were solid or aqueous, alcoholic or hydroalcoholic fluid extracts of soluble plant or animal constituents. During this period, the use of plants and animals or their parts were abandoned for the more concentrated extracts. Plant extracts can be used for scientific testing, to find out which nutrients or chemicals are present in the plant. Plant extracts are also used in some beauty products (shampoos, soaps, perfumes), medicines, or food flavoring (like vanilla extract). Different pharmaceutical dosage forms or preparations were originally designed to extract and concentrate the active drug principles like alkaloids, glycosides and volatile oils primarily from plants and used for therapy (http:/www.mosby.com/MERLIN/drug_ca rd_update/history_drug_development.htm.) These preparations greatly decreased the 
dosage amount and showed increased therapeutic effects. These preparations were in the crude forms of plant or animal material and the main types of these preparations are described as below (Koul et al., 2005).

Plant extract preparations :

Aromatic waters: Saturated solutions of volatile plant oils or other volatile substances in water, e.g., rose water.

Decoctions: Soluble principles ofplant or animal parts extracted with boiling water, e.g., Terminalia decoction.

Elixirs: Aromatic and sweetened hydroalcoholic liquids that contain one or more ingredients, e.g., cinchona alkaloid elixir.

Extracts: These are primarily semisolids or solids obtained by extracting the active principles from plant or animal parts with a suitable solvent and allowing the solvent to evaporate, e.g., belladonna and liver extract.

Fluid extracts: Alcoholic or hydroalcoholic extracts from plant principles in which $1 \mathrm{ml}$ of fluid extract is obtained from $1 \mathrm{~g}$ of plant, e.g., gelsemium fluid extract.

Infusions: Soluble plant principles extracted by soaking the plant in hot water, e.g., digitalis infusion.

Liniments: Liquid preparations containing drug(s) applied to the skin with rubbing, e.g., camphor and belladonna liniment.

Mixtures: Aqueous suspensions intended for oral administration that contain insoluble drug(s).

Ointments: Semisolid preparations of drug(s) in a greasy base that liquefy after application to the skin.

Powders: Solid mixtures of finely powdered drugs intended for oral use.

Tinctures: Alcoholic or hydroalcoholic extracts made from 10 to $20 \mathrm{~g}$ of dried plant per 100 $\mathrm{ml}$, e.g., tincture of belladonna (http:/www.mosby.com/MERLIN/drug_card_update/ history_drug_development.htm.)

For safety, do not ingest any extract you make, since you do not know which chemicals are present in the plant and many plant chemicals are poisonous.

In the last years, the use of plant extracts, as well as other alternative forms of medical treatments, is enjoying great popularity all over the world. Aromatic plants have been used for generations not simply as food ingredients but also to treat a plethora of ailments and, in recent times, scientific data are accumulating that demonstrate for many herbs and related essential oils medicinal properties useful in the prevention of diseases or in the relieve of their symptoms (Tognolini et al., 2006). Essential oils, mixtures of natural volatile compounds deriving from plant secondary metabolism, mainly monoterpenes, sesquiterpenes, and their oxygenated derivatives (alcohols, aldehydes, esters, ethers, ketones, phenols and oxides), are isolated by steam distillation and have been known since antiquity to possess antibacterial and antifungal properties (Lopes-Lutz et al., in press). 
Generally, the oil composition is a balance of various compounds, although in many species one constituent may prevail over all others. Changes in the essential oil compositions might arise from several environmental, chemical, seasonal, geographical and genetic differences (Delamare et al., 2007). Essential oils antimicrobial, antioxidant, anti-inflammatory, antispasmodic and relaxing properties have been described both in animals and humans (Tognolini et al., 2006).

Research laboratories worldwide have found literally thousands of phytochemicals which have in vitro inhibitory effects on all types of organisms. These in vitro screening programs, using the ethnobotanical approach, are important in validating the traditional use of herbal remedies and for providing leads in the search for new active substances. Whereas activity identified by an in vitro test does not necessarily confirm that a plant extract is an effective medicine, nor a suitable candidate for drug development, it does provide basic understanding of a plant efficacy and in some cases toxicity. However, more of these compounds should be subjected to animal and human studies to determine their effectiveness in whole organism systems, including particular toxicity studies as well as an evaluation of their effects on normal microbiota. The non prescription use of medicinal plants is cited today as an important health problem, in particular their toxicity to the kidneys (Mendonça-Filho, 2006).

A number of aromatic medicinal plants used for treating infectious diseases have been mentioned in different phytotherapy manuals due to their availability, fewer side effects, and reduced toxicity (Almeida et al., 2006).

Although, essential oil of oregano and its component carvacrol slightly increased the incidence of apoptotic cell death, they showed extensive antimicrobial activity even at lower concentrations (Dusan et al., 2006). Relatively high cytotoxicity was demonstrated by thyme oil, which increased both apoptotic and necrotic cell death incidence.

\section{Crude extracts}

Traditional medicines differ from the modern medicines in that the starting point is a history of observation of the effects of plant or animal materials on humans, and it uses crude extracts that are complex mixtures of naturally- occurring compounds, as opposed to single pure compounds of synthetic origin. Now there is increasing evidence that many current chemically synthesized medicines simply suppress symptoms of the diseases and ignore the underlying causes. In contrast traditional medicines, including herbal and glandular products, appear to address the cause of many diseases and yield superior clinical results. Therefore, crude plant extracts in the form of decoction, infusion or tincture are traditionally more used by the population for the treatment of several diseases, as well as an antiinflammatory and healing agent (Holetz et al., 2005). As a general rule crude therapeutic products are less toxic than their synthetic counterparts because they contain the total family of medicinal compounds (known and unknown) just as they are found in their natural source and hence offer less risk of side effects. In crude preparations, perhaps, the other components that are present in addition to the active components may be affecting the effects of the active components. These known and unknown components might be acting as synergists for the therapeutic effects and antagonists for the side effects of the active components as well as the other toxic components in the crude preparation (Koul et al., 
2005). They may be involved in the gastrointestinal absorption and determination of target sites for the active components too. Also it has been reported that most of botanical dietary supplements often contain complex mixtures of phytochemicals that have additive or synergistic interactions. For example, the tea catechins include a group of related compounds with effects that are demonstrable beyond those that are seen with epigallocatechin gallate, the most potent catechin. The metabolism of families of related compounds may be different than the metabolism of purified crystallized compounds (Heber, 2003).

It is generally accepted that the active principles (whether natural or synthesized) may be more toxic than the whole extract or its crude form (Saxena, 1985). Perhaps other ingredients present in the crude extract modulate the toxicity of the active principle. The Ayurvedic remedy worked almost as well as the conventional drug but with fewer side effects (Brown, 1995).Sharma et al., (2000) have reported the protective effect of crude, Emblica myrobalan, Emblica officinalis Gaertn. (Hindi: Amla) extract and its major active component ascorbic acid on the in vivo clastogenicity of two chemicals namely Benzo(a)pyrene (a well-known carcinogen) and Cyclophosphamide (an anticancer drug) in mice. The extent of chromosomal aberrations (CAs) and the frequencies of micronucleated polychromatic erythrocytes (MnPCEs) were taken as an index of clastogenecity in their investigation. They observed that the crude extract of amla showed a higher protection than its principle component, ascorbic acid. Ascorbic acid alone did not show any significant inhibitory effect on CAs or MnPCEs induced either by Benzo(a)pyrene or Cyclophosphamide.

This clearly reflected that the inhibitory effects are related to the total activity of the crude extract, rather than that of a single major component (Sarkar et al., 1996). In fact, purified form of ascorbic acid has been reported to enhance the clastogenic and carcinogenic effects of some chemicals (Dhir et al., 1990). Rossner et al., (1988) observed ascorbic acid to be ineffective in reducing CAs in occupationally exposed workers. It has been reported that ascorbic acid has a non-significant effect on the antioxidant defense system in mice, whereas the crude amla extract do enhance the reduced glutathione contents as well as the activities of glutathione-S-transferase, glutathione reductase and glutathione peroxidase, suggesting that the anti- oxidant activity is mainly due to the presence of other compounds present in amla (Jeena et al., 1999; Sharma et al., 2000). Ascorbic acid has also been shown to antagonize the toxic effects of certain metallic salts in mammalian systems as well as (Chakrabarty, 1977). However, studies performed with equivalent amount of synthetic ascorbic acid as present in crude fruit extract showed that it was not as effective as the extract in reducing the metal toxicity in mice (Dhir et al.,1990, 1991).

\section{Toxicity risk of plant extract}

The belief that natural medicines are much safer than synthetic drugs has caused exceptional growth in human exposure to natural products, as plants, phytotherapeutic agents, and phytopharmaceutical products. This fact has lead to a resurgence of scientific interest in their biological effects. In most countries there is no universal regulatory system insuring the safety and activity of natural products and they had not been sufficiently investigated analytically or toxicologically (Valerio Jr.\&Gonzales, 2005). Herbal medicines can be potentially toxic to human health. In this way, scientific research has shown that 
many plants used in traditional and folk medicine are potentially toxic, mutagenic, and carcinogenic (Mengs, 1988., Ferreira-Machado et al, 2004).

Based on their long-term use by humans, one might expect herbs used in traditional medicine to have low toxicity. Nevertheless, some of them can cause adverse effects or have the potential to interact with other medications (Zink\&Chaffin, 1998); moreover, there is little information on the potential risk to health of such herbs (Basaran et al., 1996). Recent investigations have revealed that many plants used as food or in traditional medicine have mutagenic, cytotoxic and genotoxic effects in vitro and in vivo assays (Plewa\&Wagner, 1993; Higashimoto et al., 1993; Schimmer et al., 1994; Zink\&Chaffin, 1998). This raises concern about the potential mutagenic or genotoxic hazards resulting from the long-term use of such plants and their use has been correlated with high rate of tumor formation in some human populations (Schimmer et al., 1994; Askin Celik\&Aslanturk, 2007a; Ames, 1986; De Śa Ferreira \& Ferrãro Vargas, 1999; Wynder et al., 1983). Assessment of the potential genotoxicity of traditional medicines is indeed an important issue as damage to the genetic material may lead to critical mutations and therefore also to an increased risk of cancer and other diseases. Direct interaction between a DNA-reactive agent and DNA is one of several pathways that may lead to primary DNA damage, because major end-points measured in the comet assay such as DNA strand breaks (which could also reflect repair incisions) and alkali-labile sites may also follow from other more indirect events such as cytotoxicity. A situation where DNA damage appears without concomitant cytotoxicity is then obviously of greater concern than a situation where DNA damage only occurs when there are simultaneous overt signs of cytotoxicity (Galloway et al., 1998; Galloway, 2000), and this is true also when evaluating the potential DNA damaging effects of plant extracts containing a plethora of more or less potent bioactive compounds (Demma et al., 2009).

The continuing growth in human exposure to natural products originating from traditional medicines has led to a resurgence of the scientific interest in their biological effects. Its scientific perspective deals with the search for various active components and understanding its mechanism of action to encourage the medicinal use. Under certain conditions, plant products may induce mutagenic, genotoxic and cytotoxic effects, due to the presence of multiple biological properties. Specific biological action of a drug is due to its specific binding to a functional molecular receptor. In complex plant extracts, the variable observed effects can be attributed to the many chemically reactive species that are formed during the processing and ingestion of the extract, which could act as non-specific redox agents, scavengers of free radicals, and ligands for binding to toxicants. The final effects are obviously the outcome of interactions between the components and their individual and collective interaction with the toxicant. The specificity and efficacy of such responses will be influenced also by the physiological factors influencing the plants and the process of administration of the extract.

\section{Plant extracts as genotoxic agents}

In screening for genotoxic and cytotoxic effects, extracts of different plant parts have been used, ranging from leafy vegetables, fruits, and underground storage organs to whole plants. The extracts were prepared mainly in water or organic solvents. Several of these assays have indicated the involvement of certain factors that are intrinsic components of the extracts, ranging from specific compounds like ascorbic acid to vegetable fibres which could 
act as nonspecific redox agents, free radical scavengers, or ligands for binding metals or toxic principles. The possible ways in which inhibitors of genotoxic agents can act include the inhibition of interaction between genes and biochemically reactive genotoxic agent and the inhibition of metabolic activation of indirectly acting toxicants. Human cells are continuously subjected to physiological and external influences which can give rise to cytotoxic, genotoxic and oxidative damage. However, cells have sophisticated mechanisms for counteracting and minimizing these types of damage. In recent years there has been increasing understanding that dietary patterns and constituents can modulate these forms of toxicity in cells. A considerable body of epidemiological evidence indicates that diets high in fruit and vegetables are inversely related to risk of chronic, degenerative diseases such as coronary heart disease and certain cancers. Much research effort has focused on the identification of phytochemicals in fruit and vegetables that exert beneficial effects and elucidation of the mechanisms by which they inhibit cellular injury and degeneration (Sarkar et al., 2008).

Various experimental systems (e.g. membrane systems, plant test systems, cell culture, animal models, human (clinical trials) are used to study the bioactivity of these plant derived compounds. The assessment of the efficacy and safety profiles of the medicinal plants should be based on scientific evidence-based approaches including, for example, different types of well established short-term tests when evaluating the genotoxic profile of such plants. The short term tests for genotoxicity and cytotoxicity are typically used to identify potential mutagens and carcinogens, but the same methods can also be used to identify anti-genotoxic agents. The effects of toxicants can be observed at the level of chromosomes (clastogenesis) through alterations in chromosome structure (chromosomal aberrations) and number (aneuploidy, polyploidy). A wide range of short-term and longterm screening procedures is available. The most common ones use higher plants or rodents in vivo as test systems for monitoring chromosomal aberrations. Experiments with a number of crude vegetable and fruit extracts have demonstrated their anticlastogenic activities against known genotoxic agents. The individual components of the extracts - e.g., sulfhydryl and flavonoid compounds, gallic acid, ellagic acid, mucic acid, citric acid, reducing sugars, tannin-are observed to have an additive interaction with the major constituents chlorophyll and ascorbic acid, when modulating the effects of the clastogens (Leme\&Marin-Morales, 2009).

An increase in chromosomal aberrations may result from interactions of a great variety of chemical agents with DNA. According to Ishidate et al. (1988), the agents which induce an increase in the chromosomal aberrations (CA) frequency by direct or indirect mechanism may also be cytotoxic, for damage to both DNA and other cell targets (enzymes, membranes, structural proteins). CA and SCE are extremely valuable and highly relevant endpoints for the detection of potential carcinogens (Swierenga et al., 1991). Chromosomal aberrations are changes in chromosome structure resulting from a break or exchange of chromosomal material. Most of the CA observed in cells are lethal, but there are many corresponding aberrations that are viable and can cause genetic effects, either somatic or inherited (Swierenga et al., 1991).

Mitotic and replication indexes are used as indicators of adequate cell proliferation biomarkers. MI measures the proportion of cells in the M-phase of the cell cycle and its inhibition could be considered as cellular death or a delay in the cell proliferation kinetics 
(Rojas et al., 1993). A cytotoxic effect of both medicinal herbs was observed, evidenced by the decrease of the MI (Gadano et al., 2006).

\section{Plant extracts as cytotoxic agents}

Low concentrations of tobacco leaf extract exerted a stimulating effect, whereas high concentration acted as a mitodepressant, on root-tip cells of Allium sativum L. (Sopova et al., 1983). Stronger concentrations of extract of immature Solanum nigrum L. fruits reduced the intensity of mitosis in A. sativum L., whereas weaker concentrations stimulated it. The presence of a cytokinin-like substance in the extract has been suggested to be responsible (Krivokapic et al., 1970). Extracts of leaves and inflorescences of male spinach and aster plants increased the frequency of chromosomal aberrations and mutations in Welsh onion and barley, respectively, whereas the female plants inhibited the processes (Sidorskii, 1984). Cellular damage including heavy pycnosis, clumping of chromosomes, fragmentation, and spindle disturbances in Allium сера L. root meristem were induced by the leaf extract of Ricinus communis L. (George \& Geethamma, 1990). Abraham and Cherian (1978) investigated the cellular changes produced by extracts of betel leaves on root tip cells of onion and demonstrated the cytotoxicity of such extracts. Chromosome-breaking activity has been exhibited by aqueous extract of mushroom (Paxillus involutus) in dry and presoaked seeds of Nigella damascena L. (Gilot-delhalle et al., 1991).

Extracts of Vicia faba L. roots and leaves and Zea mays L. leaves were compared for their ability to induce chromosomal aberrations and sister-chromatid exchanges in Chinese hamster ovarian cells and human lymphocytes. Both the extracts induced CAs in both systems; however, maize extract was more potent than Vicia extract (Kanaya et al., 1992). Aqueous extract of Heliotropium curassavicum L., though employed widely in therapeutics, has been found to induce chromosomal aberrations and anaphase delay in $\mathrm{CHO}$ cell line. This toxic effect was associated with the pyrrolidizing alkaloids and the $\mathrm{N}$ - oxides, which are changed into pyrrolic derivatives through a process of in vitro metabolism (Carballo et al., 1992).

As mentioned earlier, extensive use is made of plant products in traditional systems of medicine and as part of life style. A limited screening of some of these products indicates a combination of effects. Chili and its pure alkaloid capsaicin, and ginger and its phenolics gingerol and shogaol are mutagenic. Turmeric (Curcuma longa L.) and its pure components are non-mutagenic and suppress the mutagenicity of chili and capsaicin and also of several mutagens and carcinogens such as tobacco, cigarette, and benzo(a)anthracene. A diet that included 1\% turmeric reduced BaP-and DMBA-induced stomach tumours and spontaneous mammary tumours in mice (Nagabhushan \& Bhide, 1985; Nagabhushan et al., 1987a, 1987b). Crude aqueous extracts of Areca catechu L. and Nicotiana tabacum L. leaf given separately were mitogenic and also increased nuclear DNA content. Tobacco, in any combination of chewing mixture, induced duration-dependent clastogenicity. The addition of high lime and betel leaf (Piper betel L.) to the quid reduced the degree of mitogenicity and induction of aneuploidy but was ineffective when both tobacco and areca nut were added to the quid (Sen et al., 1987, 1991).

Higher plants, even showing low concentrations of oxidase enzymes and alimitation in the substrate specification in relation to other organism groups, present consistent results that may serve as a warning to other biological systems, since the target is DNA, common to all 
organisms. Among the plant species, Alium cepa and Vicia faba have been used to evaluate DNA damages, such as chromosome aberrations and disturbances in the mitotic cycle. The mitotic index and some nuclear abnormalities are used to evaluate cytotoxicity, genotoxicity and analyze micronucleus to verify mutagenicity, of different chemicals. The mitotic index (MI), replication index $(\mathrm{RI})$, and micronucleus $(\mathrm{MN})$ analysis methods are cytogenetic tests that are used both in vivo and in vitro. MI measures the proportion of cells in the M-phase of the cell cycle and its inhibition could be considered as cellular death or delay in the cell proliferation kinetics (Rojas et al. 1993). RI measures cell division kinetics by counting the percent of cells in first, second, third or more metaphase (Holland et al. 2002). MI frequencies and RI values decreased with increasing extracts of $H$. pallasii, $H$. plicatum subsp. polyphyllum, H. plicatum subsp. pseudoplicatum, H. goulandriorum (Eroğlu et al., 2010). This state can explain with two different mechanisms: cellular death and decreasing of cell divisions. The results point to cytotoxic as well as antiproliferative effects and suggest that extracts of these species. $\mathrm{MN}$ is a small extra nucleus separated from the main one, generated during cellular division by lagging chromosomes or by chromosome fragments. A negative correlation was observed between $\mathrm{MN}$ induction and cell proliferation; the higher the MN frequency detected in exposed individuals, the lower the values of nuclear division progression expressed as RI. In living creatures, which are exposed to a mutagen factor, the probability of formation of mitotic and meiotic defects is increased and the rate of MN could increase due to this increase (Ramalho et al. 1988). This may mean that cells with greater chromosomal damage may die before cell division or may be less capable to enter this phase (Santos-Mello et al., 1974). Multiple MN as the result of the loss of large part of the genome impairs or even prevents cell division (Nath \& Ong, 1990).

\section{Plant extracts as clastogenic agent}

Genotoxins can induce mutations in chromosomes (clastogenesis) or in a small number of base pairs (mutagenesis). Genotoxic agents include X-rays, natural carcinogens, some manmade products (e.g. acridine and vinyl chloride), and viruses. The effects of toxicants can be observed at the level of chromosomes (clastogenesis) through alterations in chromosome structure (chromosomal aberrations or CA) and number (aneuploidy, polyploidy). The clastogenic effects caused by the extracts from plant extracts species included anaphase/telophase bridges, chromosome fragments and sticky chromosome. Babich et al. (1997) reported that metaphases with sticky chromosomes lose their normal appearance and appear to have a sticky "surface" which causes chromosome agglomeration, possibly due to effects on chromatin and chromosome organization. Singh (2003) states that the presence of chromosome fragments is an indication of chromosome breaks, and can be a consequence of anaphase/telophase bridges.Many plant extracts and their active principles have been described and utilized as therapeutic agents. There is considerable interest in determining the risks that these products may pose to health, because many of these plants contain compounds which are known to cause diseases or even death in animals and humans. Thus, an assessment of their cytotoxic and mutagenic potential is necessary to ensure a relatively safe use of medicinal plants (Surh \& Ferguson, 2003).

Plant test system is widely used for monitoring genotoxicity of chemicals because of many advantages such as low cost, easily available throughout the year, ease to handle, good chromosome condition for the study of chromosome damage and above all good correlation 
with other test systems. A wide range of short-term and long-term screening procedures is available. The most common ones use higher plants (Allium cepa, Allium sativum, Vicia faba, Tradescantia virginiana) or rodents (mice, rats) in vivo as test systems for monitoring chromosomal aberrations (Hsu, 1982; Kihlman, 1971; Levan, 1949; Naismith, 1987; Sharma \& Sharma, 1989). Root tip cells of $V$. faba constitute an excellent system for such cytogenetic tests (Abraham \& John 1989; Gowrisankar et al., 1993; John \& Abraham 1991; Upadhya et al., 1996; Wuu \& Grant 1967). However WHO (1971) and Committee 17 (1975) argued that a single test system is not sufficient to come to the conclusion that a particular agent is mutagenic or not. Moreover all these plants are internally used for treatment of various diseases (Sinha, 1996) posing definite risk if they contain toxic substances. Therefore further tests of these plants using mammalian test system were conducted. For examples, fifty percent ethanol extracts of N. odorum and S. indicum, dried and dissolved in PBS, induced significant increase in frequencies of bone marrow micronuclei, bone marrow chromosome aberrations and synaptonemal complex damages when given as i.p. injection to mice (in preparation) (Sobita \& Bhagirath., 2005) . Confirmed mutagenicity on the one hand and medicinal importance on the other hand these plants have made it necessary to isolate the active priciples.

Human cells are continuously subjected to physiological and external influences which can give rise to cytotoxic, genotoxic and oxidative damage. However, cells have sophisticated mechanisms for counteracting and minimizing these types of dam age. In recent years there has been increasing understanding that dietary patterns and constituents can modulate these forms of toxicity in cells. A considerable body of epidemiological evidence indicates that diets high in fruit and vegetables are inversely related to risk of chronic, degenerative diseases such as coronary heart disease and certain cancers.Much research effort has focused on the identification of phytochemicals in fruit and vegetables that exert benefcial effects and elucidation of the mechanisms by which they inhibit cellular injury and degeneration. Various experimental systems (e.g. membrane systems, cell culture, animal models, human clinical trials) are used to study the bioactivity of these plant- derived compounds. There are, of course, advantages and limitations to all of these systems. Cell-culture models have a number of advantages over other experimental systems, including avoidance of ethical issues relating to animal or human studies, ability to cryopreserve cell lines, ability to conduct mechanistic studies at molecular level, ease of control of the experimental environment and cost (Walum et al, 1990).

However, cell-culture systems cannot replicate conditions found in the body, e.g. systemic functions such as the nervous and endocrine systems are missing. Thus control of cellular metabolism may be more constant in vitro and the cultured cells will not be fully representative of the tissue from which they were derived. Provided the limits of the model are appreciated, cell culture is a valuable, if not the most valuable, tool in biomedical science (O'Brien et al, 2000).

In vitro studies using leukocytes or cell lines are relatively rare. The genotoxicity of $P$. granantum has also been reported by Settheetham \& Ishida (1995), who, using in vitro assays, showed that the administration of an aqueous pomegranate fruit peel extract induced apoptosis in human cells. On the contrary, Amorin (1995) did not observe genotoxic effect using $\mathrm{MN}$ assay in mouse treated orally with fruit aqueous extracts of this plant at dose of 1000 and $2000 \mathrm{mg} / \mathrm{kg}$ b.w. The data presented here show that the P. granatum L. fruit 
hydroalcoholic extract can induce genetic damage at different expression levels: recombinogenic, mutagenic and clastogenic. These results indicate that the use of this extract carries a genetic risk and an analysis of the risk-benefit balance appears to be crucial (S’anchez-Lamar et al., 2008).

Carthamus lanatus L. (Asteraceae) is known as a plant of phytopharmaceutical importance with sedative, anti-tumor and interferon-inducing activities (Benedi et al., 1986; Yasuhuko et al., 1979). Recently, a variety of biological activities of C. lanatus, including antioxidant, antibacterial, anti- fungal activity and cytotoxicity were shown (Taskova et al., 2002, 2003; Mitova et al., 2003). Some data about the closely related C. tinctorius were reported. Ames test and Salmonella microsome reversion assay (Morimoto et al., 1982) showed a mutagenic effect of the water extract of $C$. tinctorius flowers, which was confirmed by Esmaili-rad et al. (1995). Yin et al. (1991) demonstrated that the water extract was negative in the Ames test but positive in the chromosomal aberration and micronucleus assay in mice. The results of Nobakht et al. (2000) indicated harmful effects on cellular growth and differentiation during the embryonic development.The clastogenic effect of total dichloromethane, methanol and water extracts, four bioactive fractions and three individual constituents from Carthamus lanatus aerial parts were evaluated in mice by bone marrow chromosome aberration assay with mitomycin $\mathrm{C}$ as positive control. Significant differences in the percentage of aberrant mitosis of the extracts were observed. The dichloromethane extract exhibited a considerable clastogenic effect and the water extract a negligible one. Different types of chromosome aberrations and time-dependant effects for the active fractions and individual compounds were found (Topashka-Ancheva et al., 2003).

Clastogenic i.e. chromosome damaging substances are present in the plasma of patients with a variety of pathological conditions accompanied by oxidative stress (Emerit, 2007). The formation of clastogenic factors (CF) and their damaging effects are mediated by superoxide, since superoxide dismutase is regularly protective. CF are produced via superoxide and stimulate the production of superoxide by monocytes and neutrophils. These results in a selfsustaining and longlasting process of clastogenesis, which may exceed the DNA repair system and ultimately lead to cancer (Emerit, 1994). An increased cancer risk is indeed observed in conditions accompanied by $C F$ formation. These include irradiated persons, patients with chronic inflammatory diseases, HIV-infected persons and the chromosomal breakage syndromes ataxia telangiectasia, Bloom's syndrome and Fanconi's anemia. Biochemical analysis has identifi ed lipid peroxidation products, arachidonic acid metabolites, nucleotides of inosine and cytokines, in particular tumor necrosis factor alpha, as the clastogenic and also superoxide stimulating components of CF. Due to their chromosome damaging effects, these oxidants can be detected with classical cytogenetic techniques (Emerit, 2007).

When testing the potential DNA-damaging effects by pharmaceutical drugs and other chemicals, the test systems are generally based on experimental animals, bacteria or various kinds of transformed cells. The major objective of our in vitro studies is to improve the risk assessment regarding exposures to genotoxic agents. From point of view of risk assessment, it is important to differ between genotoxic carcinogens and other substances that increase the risk of cancer by other mechanisms. In the case of drug-induced oxidative DNAchanges, for instance, one can distinguish two different main groups of substances: those who cause various types of reactive oxygen radicals in the cells directly and those who 
cause oxidative stress indirectly, as a consequence of general cytotoxicity. The research of recent years has also shown that the DNA repair has a great impact on whether the DNAdamage is manifested as a mutation or not, and there is reason to believe that there is a great variation in individual sensitivity to genotoxic agents, due to individual differences in DNA repair, metabolic bioactivation/detoxification pattern and/or other defense mechanisms in the cells.

Specific biological action of a drug is due to its specific binding to a functional molecular receptor. In complex plant extracts, the variable observed effects can be attributed to the many chemically reactive species that are formed during the processing and ingestion of the extract, which could act as non-specific redox agents, scavengers of free radicals, and ligands for binding to toxicants. The final effects are obviously the outcome of interactions between the components and their individual and collective interaction with the toxicant. The specificity and efficacy of such responses will be influenced also by the physiological factors influencing the plants and the process of administration of the extract (Sarkar et al., 1996).

Much research effort has focused on the identification of phytochemicals in fruit and vegetables which exert beneficial effects. In a recent project, we are currently also evaluating the genotoxic and antigenotoxic effects of some plant extracts used in traditional medicine in Turkey, and in these studies we also include fractions of extracts and/or pure compounds from extracts. Our researches has focused on the cytoprotective, antioxidant and o cytotoxic and antigenotoxic effects of plant extracts in meristematic cell systems and human peripheral lymphocytes which is important in helping to understand the fundamental mechanisms of action of these compounds. Our data add to the body of evidence supporting dietary guidelines to increase fruit and vegetable intake. First, the potential beneficial effects of phytochemicals are demonstrated. For example, lycopene are reported to exhibit a wide variety of biological effects, including antioxidant and free-radical scavenging activities (Aslanturk \& Aşkın Çelik, 2005, 2006). Secondly, we illustrate the use of meristematic cellular models to study plant extracts-induced genotoxicity and cytotoxicity (Aşkın Çelik \& Aslanturk, 2007b, 2009a, 2009b, 2010; Özmen \& Çelik Aşkın, 2007). However, working with crude extracts, also means working with complex mixtures of biologically active compounds. Some of the compounds in such a mixture can be cytotoxic and/or genotoxic, others can be cytoprotective and/or anti-genotoxic.

Our findings show that plant extracts evaluated have a genotoxic potential in vitro which calls for a more thorough safety evaluation. Such evaluation should include other endpoints of genotoxicity apart from DNA damage, and possibly also pure compounds. The inhibitory action tends to lower the active dose of genotoxic agents and the accelerating action raises it. The ultimate load of mutations is the result of interaction between these opposing forces, modified by a large number of exogenous and endogenous factors. Therefore, a comprehensive overview is needed before arriving at conclusions regarding the environmental safety of any new chemical. The determination of genetic biomarkers would help estimate the potential toxicity of medicinal herbs in order to regulate medicinal plant consumption, which would be an important measure of public health protection. Thus, caution regarding the indiscriminate use of medicinal plants by the population remains a necessity. 


\section{Acknowledgements}

The author wish to thank Research Asisstant Dr. Özlem Sultan ASLANTÜRK for her helpful advice in this chapter.

\section{References}

Abraham, S. \& Cherian,V. D. (1978). Studies on cellular damage by extracts of betel leaves used for chewing. Cytologia, 43, 203-208.

Abraham, S. \& John, A.T. (1989). Clastogenic effects produced by black pepper in mitotic cells of Vicia faba. Mut. Res., 224, 281-285.

Agarwal, K., Dhir, H., Sharma, A. \& Talukder, G. (1989). Comparison of the modification of $\mathrm{Ni}$ and $\mathrm{Pb}$ clastogenicity by plant extract and essential metals. pp 1303-1311 in Anke, M., Baumann,W., Braunlick, H., Brauckner,C., Grappel,B.\& Grun,M.eds., Proceedings of the 6 th International Trace Element Symposium. Vol. 4. Friedrich-Schieler Universitat, Jena.

Almeida, C.F.C.B.R., Amorim, E.L.C.; Albuquerque, U.P. \& Maia, M.B.S. (2006). Medicinal plants popularly used in the Xingó region - a semi-arid location in Northeastern Brazil. J. Ethnobiol Ethnomed., 2, 1-7.

Amonkar, A. J. \& Bhide, S.V. (1987a). Mutagenicity of gingerol and shagaol and antimutagenicity of zingerone in Salmonella microsome assay. Cancer Lett., 36, 221233.

Amorin, A. (1995). Test of mutagenesis in mice treated with aqueous extracts from Punica granatum L. Revista Brasilena de Farmacia, 74, 110-111.

Ames, B. N. (1986). Food constituents as a source of mutagens, carcinogens and anticarcinogens. in Genetic Toxicology of the Diet, I. Knudsen, Ed., 55-62, Alan R. Liss, New York, NY, USA.

Askin Celik, T. \& Aslanturk, O.S. (2007a). Cytotoxic and genotoxic effects of Lavandula stoechas aqueous extracts. Biologia, 62 (3), 292-296.

Aslantürk, Ö.S. \& Çelik, T. (2005). Preventive effect of lycopene on chromosome aberrations in Allium cepa. Pakistan Journal of Biological Sciences, 8 (3), 482-486.

Aslantürk, Ö.S., \& Çelik, T. (2006). Protective effect of lycopene on Ethyl Methane Sulfonate induced chromosome cberrations in Allium cepa. Caryologia, 59 (3), 220-225.

Aslantürk, Ö.S. \& Aşkın Çelik, T. (2009b). Genotoxic and antimutagenic effects of Capparis spinosa L. on the Allium cepa L. root tip meristem cells. Caryologia, 62 (2), 114-123.

Aşkın Çelik, T. \& Aslantürk, Ö.S. (2007b). Cytotoxic and genotoxic effects of Lavandula stoechas aqueous extracts. Biologia, 62(3), 292-296

Aşkın Çelik, T. \& Aslantürk, Ö.S. (2009a). Investigation of cytotoxic genotoxic effects of Ecballium elaterium Juice based on Allium Test. Methods and Findings in Experimental and Clinical Pharmacology, 31 (9), 591-596.

Aşkın Çelik, T. \& Aslantürk, Ö.S. (2010). Evaluation of Cytotoxicity and Genotoxicity of Inula viscosa Leaf Extracts with Allium Test. Journal of Biomedicine and Biotechnology, (doi: 10.1155/2010/189252).

Babich H, Segall MA.,Fox KD. (1997). The Allium test - A simple, eukaryote genotoxicity assay. Am Biol Teach., 59:580-583. 
Basaran, A. A., Yu, T.W., Plewa, M. J. \& Anderson, D. (1996). An investigation of some Turkish herbal medicines in Salmonella typhimurium and in the COMET assay in human lymphocytes. Teratogenesis Carcinogenesis and Mutagenesis, 16 (2), 125-138.

Benedi J., Iglesias I., Manzanares J., \& Zaragoza F.(1986). Preliminary pharmacological studies of Carthamus lanatus L. Plant. Med. Phytother., 20,25-30.

Brito, M. T., Martinez, A. \& Cadavid, N. F. C. (1990). Mutagenic activity in regional foods and beverages from the Venezuelan Andean region. Mutation Research, 243 (2), 115120.

Brown, S.J. (1995) Mental health researchers explore Hindu herbs, Clin Psychiat News, 15.

Carballo, M., Mudry, M. D., Villamil, I. B. L. \& Mo D'aquino. (1992). Genotoxic action of an aqueous extract of Heliotropium curassavicum vat. argentinum. Mutation Res., 279, 245-253.

Chan, K. (2003). Some aspects of toxic contaminants in herbal medicines. Chemosphere, 52, 1361-1371.

Chakrabarty, D., Bhattacharya, A., Majumdar, K. \& Chatterjee, G.C. (1977). Effect of chronic vanadium pentoxide administeration on $\mathrm{L}$ - ascorbic acid supplementation. Int $J$ Vit Nutr Res., 47, 81-86.

Committee-17, 1975. History and rationale of genetic toxicity testing: An impersonal, and sometimes personal view. Science, 187, 503-514.

Cox, P.A. (1994) Ciba Foundation Symposium, Chichester, John Wiley \& Sons, 184, 25-44. Fransworth NR, Ciba Foundation Symposium, Chichester, John Wiley \& Sons, 1990, 154, 221.

Delamare, A.P.L. Moschen-Pistorello, I.T., Artico, L., Atti- Serafini, L. \& Echeverrigaray, S. (2007). Antibacterial activity of the essential oils of Salvia officinalis L. and Salvia triloba L. cultivated in South Brazil. Food Chem.,100, 603- 608.

Demma, J., Engidawork, E. \& Hellman, B.(2009). Potential genotoxicity of plant extracts used in Ethiopian traditional medicine. Journal of Ethnopharmacology, 122(1), 136142.

Dusan, F., Marián, S., Katarína, D. \& Dobroslava, B. (2006). Essential oils--their antimicrobial activity against Escherichia coli and effect on intestinal cell viability. Toxicology, 20, 1435-1445.

Dhir, H., Roy, A. K., Sharma, A. \& Talukder, G. (1990). Modification of clastogenicity of lead and aluminium in mouse bone marrow cells by dietary ingestion of Phyllanthus emblica fruit extract. Mutation Res., 241, 305-312.

Dhir, H., Agarwal, K., Sharma, A. \& Talukder, G. (1991). Modifying role of Phyllanthus emblica and ascorbic acid against nickel clastogenicity in mice. Cancer Lett., 59, 9-18.

Duke, J.A. (1990). Promising phytomedicinals In: Advances in new crops, [J Janick and JE Simon (eds)] Timber Press, Portland, OR, 491-498.

D'Souza, A. V. \& Bhide, S. V. (1987b). In vitro antimutagenicity of curcumin against environmental mutagens. Food Chem. Toxicol., 25, 545-547.

Emerit, I. (1994). Reactive oxygen species, chromosome mutation and cancer: possible role of clastogenic factors in carcinogenesis. Free Radic. Biol. Med., 16, 99-9.

Emerit, I. (2007). Clastogenic factors as potential biomarkers of increased superoxide production. Biomarker Insights, 2, 429- 438. 
Eroğlu, H.E., Budak, Ü., Hamzaoğlu, E.,Aksoy, A., Albayrak, S. (2010). In vitro cytotoxıc effects of methanol extracts of six Helichrysum taxa used in traditional medicine. Pak. J. Bot., 42(5), 3229-3237.

Esmaili-rad, S., Daneshvar, N., Rastegar-Lati, A. \& Mahmoudian, M. (1995). Mutagenicity screening of food coloring agents (herbal and synthetic) with Ames test. In: Proceedings of the 12th Iranian Congress of Physiology and Pharmacology. IUMS Press. Teheran, 414.

Farnsworth, N.R., Akerele, O.O., Bingel, A.S., Soejarta, D.D. \& Eno, Z. (1985). Medicinal plants in therapy. Bulletin World Health Organisation, 63, 965-981.

Fernandes De S’a Ferreira, I. C. Ferraro Vargas, V. M. 1999. Mutagenicity of medicinal plant extracts in Salmonella/microsome assay. Phytotherapy Research. 13(5), 397-400.

Ferreira-Machado, S. C., Rodrigues, M. P., Nunes, A. P. M., et al.(2004). "Genotoxic potentiality of aqueous extract prepared from Chrysobalanus icaco L. leaves," Toxicology Letters, 151(3), 481-487.

Galloway, S.M., Miller, J.E., Armstrong, M.J., Bean, C.L., Skopek, T.R., Nichols, W.W., (1998). DNA synthesis inhibition as an indirect mechanism of chromosome aberrations: comparison of DNA-reactive and non-DNA-reactive clastogens. Mutation Research. 400, $169-186$.

Gadano, A.B., Gurni, A.A., Carballo, M.A. (2006). Argentine folk medicine: Genotoxic effects of Chenopodiaceae family. Journal of Ethnopharmacology. 103, 246-251.

Galloway, S.M. (2000). Cytotoxicity and chromosome aberrations in vitro: Experience in industry and the case for an upper limit of toxicity in the aberration assay. Environmental and Molecular Mutagenesis 35, 191-201.

George, K. \& Geethamma, S. (1990). Effects of leaf extract of Ricinus communis on Allium cepa. Cytologia, 55, 391-394.

Gilot-delhalle, J., Moutschen, J.\& Moutschen-dahmen, M. (1991). Chromosome-breaking activity of extracts of the mushroom Paxillus involutus Fries ex Batsch. Experientia, 47, 282-284.

Gowrishanker, B. \& Vivekananda, O.S. (1993). Cytotoxic effects of whisky on Vicia faba in vivo. Nucleus, $36(1,2), 62-65$.

Heber, D. (2003). Herbal preparations for obesity: are they useful? Prim Care, 30 , 441-463.

Higashimoto, M., Purintrapiban, J., Kataoka, K et al., (1993). Mutagenicity and antimutagenicity of extracts of three spices and a medicinal plant in Thailand. Mutation Research, 303 (3), 135-142.

Holland, N., Duramad, P., Rothman, N. et al (2002). Micronucleus frequency and proliferation in human lymphocytes after exposure to herbicide 2, 4dichlorophenoxyacetic acid in vitro and in vivo. Mutat Res, 521: 165-178

Holetz, R.B., Nakamura, T.U., Filho, B.P.D., Melllo, J.C.P., Diaz, J. A .M., Toledo, C.E.M. \& Nakamura, C.V. (2005). Biological effects of extracts obtained from Stryphnodendron adstringens on Herpetomonas samuelpessoai. Mem. Inst. Oswaldo Cruz, v. 100, 4, 397401.

Hoyos, L.S., Au, W.W., Heo, M.Y., Morris, D.L. \& Legator, M.S. (1992). Evaluation of the genotoxic effects of a folk medicine, Petiveria alliacea (anamu). Mutation Research, 280, 29- 34.

Hsu, T. C., ed. (1982). Cytogenetic assays of environmental mutagens. Osmun Publ. 
Ishii, R., Yoshikawa, H., Minakata, N.T., Komura, K. \& Kada, T. (1984). Specificity of bioantimutagens in the plant kingdom. Agricultural and Biological Chemistry, 48, 2587-2591.

Ishidate, M., Hammois, M.C., Sofuni, T., (1988). A comparative analysis of data on the clastogenicity of 951 chemical substances tested in mammalian cell cultures. Mutation Research, 195, 151-213.

Ito, Y., Maeda, S., Souno, K., Ueda, N.\& Sugiyama, T. (1984). Induction of hepatic glutathione S-transferase and suppression of 7,12-dimethybenz(a)anthraceneinduced chromosome aberrations in rat bone marrow cells by Sudan III and related azo dyes. J. Natl. Cancer Inst., 73, 177-183.

Jeena, K.J., Joy, K.L. \& Kuttan, R. (1999). Effect of Emblica officinalis, Phyllanthus amarus and Picrorrhiza kurroa on N- nitroso-diethylamine induced hepato-carcinogenesis, Cancer Lett., 136, 11-16.

John, A.T. \& Abraham, S. (1991). Cytological changes produced by red pepper in mitotic cells of Vicia faba L. Caryologia, 44(3, 4), 325-331.

Joseph, A.A. Mosby's Nursing Drug Cards: The History of Drug Development, http://www.mosby.com/MERLIN/drug_card_update/history_drug_developmen t.htm.

Kanaya, N., Takehisa, S., Nicoloff, H., Nikolova, T. \& Damianova, V. (1992). Plant extracts induce chromosome aberrations and sister-chromatid exchanges in Chinese hamster ovary cells and human lymphocytes. Mutation Res., 281, 47-54.

Kassie, F., Parzefall, W., Musk, S et al., (1996). Genotoxic effects of crude juices from Brassica vegetables and juices and extracts from phytopharmaceutical preparations and spices of cruciferous plants origin in bacterial and mammalian cells. ChemicoBiological Interactions, 102 (1), 1-16.

Kihlman, B. A. (1971). Root tips for studying the effects of chemicals on chromosomes. Pp. 484-514 in A. Holleander, ed., Chemical mutagens: Principles and methods for their detection.Plenum, New York.

Kong, J.M., Goh, N.K., Chia, L.S. \& Chia, T.F. (2003) Recent advances in traditional plant drugs and orchids. Acta Pharmacol Sin., 24, 7-21.

Koul, A., Gangar, S.C. \& Sandhir, V. (2005). Pitfalls in Journey from Traditional to Modern Medicine. Natural Product Radiance, 4 (1), January-February.

Krivokapic, K., Hadziselimovic, R.\& Sofradzija, A. (1970). Effect of the extract from immature fruits of Solanum nigrum L.on the intensity of mitosis in Allium sativum. Iugosl. Physiol. Pharmacol. Acta, 6, 363-367.

Levan, A. (1949). The influence on chromosomes and mitosis of chemicals, as studied by the Allium test. Eighth International Congress on Genetics. Hereditas (suppl. vol.), 325337.

Lopes-Lutz, D., Alviano, D.S., Alviano, C.S. \& Kolodziejczyc, P.P. (2008). Screening of chemical composition, antimicrobial and antioxidant activities of Artemisia essential oils. Phytomedicine, 69 (8), 1732-1738

Mendonça-Filho, R.R. (2006). In: Modern phytomedicine: turning medicinal plants into drugs Bioactive Phytocompounds: New Approaches in the Phytosciences. (Ahmad, I., Aqil, F. and Owais, M., Eds.), WILEY-VCH Verlag GmbH \& Co. KGaA, Weinheim, 1-24.

Mengs, U. (1988). "Toxiceffects of sennosides in laboratory animals and in vitro," Pharmacology, 36(1).180-187, 
Morimoto, I., Watanabe, F., Osawa, T., Okitsu, T. \& Kada, T. (1982). Mutagenicity screening of crude drugs with Bacillus subtilis resassay and Salmonellas micro-study on mutagenicity of microsome reversion assay. Mutat. Res., 97, 81-102.

Nagabhushan, M. \& Bhide, S. V. (1985). Mutagenicity of chilli extract and capsaicin in shortterm tests. Environm.Mutagen, 7, 881-888.

Nagao, M., Wakabayashi, K., Fujita, Y., Tahira, T., Ochiaia, T. \& Sugimura, T. (1986). Mutagenic compounds in soy sauce, Chinese cabbage, coffee and herbal teas. In: Genetic Toxicology of theDiet, I. Knudsen, Ed., 55-62, Alan R. Liss, New York, NY, USA.

Naismith, R. W. (1987). Guidelines for minimal criteria of acceptability for selected shortterm assays for genotoxicity. Mutation Res., 189, 181-183.

Nath, C.J. \& T. Ong. (1990). Micronuclei assay in cytokinesis-blocked binucleated and conventional mononucleated methods in human peripheral lymphocytes. Teratogen Carcin Mutagen., 10, 273-279.

Nguyen, T., Fluss, L., Hodej, R., Ginther, G. \& Leighton, T. (1989). The distribution of mutagenic activity in red rose and White wines. Mutation Research, 223, 205-212.

Nobakht, M., Fattahi, M., Hoormand, M., Milanian, I., Rahbar, N. \& Mahmoudian M. (2000). A study on the teratogenic and cytotoxic effects of safflower extract. J. Ethnopharmacol., 73, 453- 459.

O'Brien, N.M., Woods, J. A., Aherne S. A., O'Callaghan, Y. C. (2000). Cytotoxicity, genotoxicity and oxidative reactions in cell-culture models: modulatory effects of phytochemicals. Biochemical Society Transactions., 28 (2), 22-26.

Özmen, A. \& Çelik Aşkın, T. (2007). Cytotoxic Effects of Peel Extracts from Citrus Limon and Citrus sinensis. Caryologia, 60 (1-2), 48-51.

Plewa, M. J. \& Wagner E. D. 1993. Activation of promutagens by green plants. Annual Review of Genetics, 27, 93-113.

Ramalho, A., Sunjevaric. I., Natarajan, A.T.(1988). Use of the frequencies of micronuclei as quantitative indicators of X-ray-induced chromosomal aberrations in human peripheral blood lymphocytes: comparison of two methods. Mutat Res, 207:141-146

Rojas, E., Herrera, L.A., Sordo, M., Gonsebatt, M.E., Montero, R., Rodriguez, R., OstroskyWegman, P., (1993). Mitotic index and cell proliferation kinetics for the identification of antineoplastic activity. Anticancer Drugs, 4, 637-640.

Rossner, P., Cerna, M., Pokorna, D., Hajek, V. \& Petr, J. (1988). Effect of ascorbic acid prophylaxis on the frequency of chromosome aberrations, urine mutagenicity and nucleolus test in workers occupationally exposed to cytostatic drugs. Mutat Res., , 208 (3-4), 149-153.

S’anchez-Lamar, A., Fonseca, G., Luis Fuentes, J ., Cozzi, R., Cundari, E., Fiore,M., Degrassi, F., Ricordy,R., Perticone R. \& De Salvia, D. (2008) Assessment of the genotoxic risk of Punica granatum L. (Punicaceae) whole fruit extracts. Journal of Ethnopharmacology, $115,416-422$.

Santos-Mello, R., D. Kwan and A. Norman. (1974). Chromosome aberrations and T-cell survival in human lymphocytes. Radiat Res., 60, 482-488.

Sarkar, D. (1992). Protective effect of crude extract of Phyllanthus emblica L. against the cytotoxicity of chlordane in mice in vivo. Perspect. Cytol.Genet., 7, 1035-1042.

Sarkar, D., Sharma, A. \& Talukder, G. (2008). Plant extracts as modulators of genotoxic effects. The Botanical Review, 62(4), 275-300. 
Saxena, R.C. (1985). Drug reactions with herbal drugs, Indian J Pharmacol., 17, 165-169.

Schimmer, O., Kruger, A., Paulini, H. \& Haefele, F. (1994). An evaluation of 55 commercial plant extracts in the Ames mutagenicity test. Pharmazie, 49 (6), 448-451.

Sen, S., Talukder, G. \& Sharma, A. (1987). Potentiation of betel-induced alterations of mouse glandular stomach mucosa by tobacco in studies simulating betel addiction. Intl. J. Crude Drug Res., 25, 209-215.

Sen, S., Talukder, G. \& Sharma, A. (1991). Betel cytotoxicity: further evidence from mouse bone marrow cells. Intl. J. Pharmacog., 29, 130-140.

Sharma, A., \& A. K. Sharma. (1989). Genetic toxicology testing of hazardous materials and wastes. Pages 281-293 In: Majumdar, S. K., Miller, E. W. \& Schmalz, R. F., eds., Management of hazardous materials and wastes: treatment, minimization and environmental effects. Pennsylvania Academy of Sciences, Harrisburg.

Sharma, N., Trikha, P., Athar, M. \& Raisuddin, S. (2000). Inhibitory effect of Emblica officinalis on the in vivo clastogenicity of benzo[a]pyrene and cyclophosphamide in mice. Hum Exp Toxicol., 19, 377-384.

Sidorskii, A. G. (1984). Effects of extracts from vegetative and generative organs of dioecious plants on the frequency of mutagen-induced chromosome aberrations and mutagenesis in plants. Genetika, 20, 1507-1510.

Singh, R.J. (2003). Plant cytogenetics. Pp. 463, CRC Press, Boca Raton,.

Sobita, K. \& Bhagirath, T.H. (2005). Effects of some medicinal plant extracts on Vicia faba root tip chromosomes. Caryologia, 58(3), 255-261.

Sopova, M., Sekovski, Z.\& Jovanovska, M. (1983). Cytological effects of tobacco leaf extract on root-tip cells of Allium sativum. Acta Biol. Med. Exp., 8, 49-56.

Surh, Y. \& Ferguson, L.R. (2003). Dietary and medicinal antimutagens and anticarcinogens: Molecular mechanisms and chemopreventive potential - highlights of a symposium. Mutat. Res., 523-524, 1-8.

Swierenga, S.H.H., Heddle, J.A., Sigal, E.A., Gilman, J.P.W., Brillinger, R.L., Douglas, G.R., Nestmann, E.R. (1991). Recommended protocols based on a survey of current practice in genotoxicity testing laboratories. IV. Chromosome aberrations and sister-chromatid exchange in Chinese hamster ovary, V79 Chinese hamster lung and human lymphocyte cultures. Mutation Research, 246, 301-322.

Taskova, R., Mitova, M., Najdenski, H., Tzvetkova, I. \& Duddeck, H. (2002). Antimicrobial activity and cytotoxicity of Carthamus lanatus. Fitoterapia, 73, 540-543.

Tognolini, M., Barocelli, E., Ballabeni, V., Bruni, R., Bianch, A.,Chiavarini, M. \& Impecciatore, M. (2006). Comparative screening of plant essential oils: Phenylpropanoid moiety as basic core for antiplatelet activity. Life Science, 78, 14191432.

Topashka-Anchevaa, M., Taskovab, R., Handjievac, N., Mikhovac, B., Duddeckd, H. (2003). Clastogenic Effect of Carthamus lanatus L. (Asteraceae).Verlag der Zeitschrift für Naturforschung, Tübingen http://www.znaturforsch.com

Upadhya, T.T., Daniel, T., Sudalai, A., Ravindraanthan, T., and Sabu, K.R. (1996) Natural kaolinitic clay: A mild and efficient catalyst for the tetrahydropyranylation and trimethylsilylation of alcohols. Synthetic FCommunications, 26, 4539-4544.

Valerio Jr, G., Gonzales, G. F. (2005). "Toxicological aspects of the South American herbs cat's claw (Uncaria tomentosa) and maca (Lepidium meyenii): a critical synopsis," Toxicological Reviews, 24(1), 11-35. 
Walum, E., Stenberg, K. and Jenssen, D. (1990). Understanding Cell Toxicology, Ellis Horwood, London

World Health Organization. (1971).Technical report no. 482.

Wuu, K.D. \& Grant, W.F. (1967). Chromosomal aberrations induced in somatic cells of Vicia fava by pesticides. Nucleus, 10(1), 37-46.

Wynder, E. L., Hall, N. E. L. \& Polansky, M. (1983). Epidemiology of coffee and pancreatic cancer. Cancer Research, 43 (8), 3900-3906.

Yasuhuko, K., Kanagawa, Y., Seishi, K., \& Takashii H. (1979). Wasserlöslicher Interferoninduktor, Verfahren zu seiner Gewinnung und dessen Verwendung. Ger Offen 3,004,018 Appl. 07 Feb.

Yin, X. J., Liu, D., Wang, H. C. \& Zhou, Y. (1991). A study on mutagenicity of 102 raw pharmaceuticals used in Chinese traditional medicine. Mutat. Res., 260, 73-82.

Zink, T. \& Chaffin, J. (1998). Herbal health products: what family physicians need to know. American Family Physician., 58 (5), 1133-1140.

http:/ / herbalgram.org/naturemade/herbclip/review.asp?i=41574. 


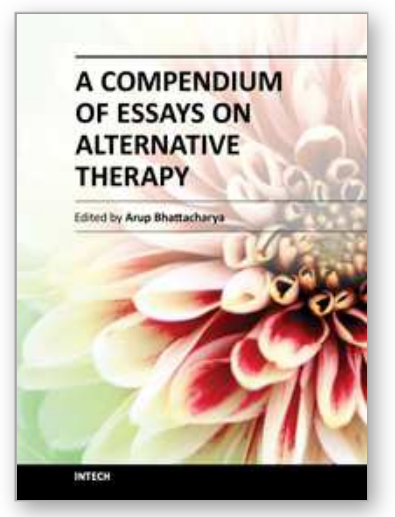

\author{
A Compendium of Essays on Alternative Therapy \\ Edited by Dr. Arup Bhattacharya
}

ISBN 978-953-307-863-2

Hard cover, 302 pages

Publisher InTech

Published online 20, January, 2012

Published in print edition January, 2012

A Compendium of Essays on Alternative Therapy is aimed at both conventional and alternate therapy practitioners, besides serving as an educational tool for students and lay persons on the progress made in the field. While this resource is not all-inclusive, it does reflect the current theories from different international experts in the field. This will hopefully stimulate more research initiatives, funding, and critical insight in the already increasing demand for alternate therapies that has been evidenced worldwide.

\title{
How to reference
}

In order to correctly reference this scholarly work, feel free to copy and paste the following:

Tülay Askin Celik (2012). Potential Genotoxic and Cytotoxic Effects of Plant Extracts, A Compendium of Essays on Alternative Therapy, Dr. Arup Bhattacharya (Ed.), ISBN: 978-953-307-863-2, InTech, Available from: http://www.intechopen.com/books/a-compendium-of-essays-on-alternative-therapy/potential-genotoxic-andcytotoxic-effects-of-plant-extracts

\section{INTECH}

open science | open minds

\section{InTech Europe}

University Campus STeP Ri

Slavka Krautzeka 83/A

51000 Rijeka, Croatia

Phone: +385 (51) 770447

Fax: +385 (51) 686166

www.intechopen.com

\section{InTech China}

Unit 405, Office Block, Hotel Equatorial Shanghai

No.65, Yan An Road (West), Shanghai, 200040, China

中国上海市延安西路65号上海国际贵都大饭店办公楼 405 单元

Phone: +86-21-62489820

Fax: $+86-21-62489821$ 
(C) 2012 The Author(s). Licensee IntechOpen. This is an open access article distributed under the terms of the Creative Commons Attribution 3.0 License, which permits unrestricted use, distribution, and reproduction in any medium, provided the original work is properly cited. 